\title{
The effect of dexketoprofen on ischemia reperfusion injury
}

\author{
Yildirim $\mathrm{Y}^{1}$, Karakaya $\mathrm{D}^{1}$, Kelsaka E ${ }^{1}$, Aksoy A ${ }^{2}$, Gülbahar $\mathrm{MY}^{3}$, Bedir $\mathrm{A}^{4}$ \\ Ondokuz Mayis University, Faculty of Medicine, Department of Anesthesiology, Samsun, Turkey. \\ dkarakaya65@gmail.com
}

\begin{abstract}
Objective: The purpose of this study was to demonstrate the effects of dexketoprofen on experimental ischemia/reperfusion injury induced in rat testicles.

Methods: Twenty-four male Wistar albino-type rats were randomly separated into three groups. To develop testicular torsion, the right testicle was rotated $720^{\circ}$ clockwise. After five hours of rotation, reperfusion was applied for 24 hours. The control group rats (Group C) had no procedures or treatments; basal numbers were used. Intraperitoneal $25 \mathrm{mg} / \mathrm{kg}$ dexketoprofen (1cc) (Group D) or the same volume of serum physiologic (GroupSP) were given to the Group Dand Group SP rats 40 minutes before and 12 hours after detorsion. Twenty-four hours after detorsion, histopathological evaluation was performed by bilateral orchiectomy. Malondialdehyde (MDA) levels were detected in testicular tissue and in serum. Results: Histopathologic changes in the spermatic cells of torsioned testicles in Group D were significantly less than those of Group SP $(p<0.05)$. MDA levels in both testicles in Group D were similar to those of the control group. Although they were lower than Group SP, the difference was not statistically significant. Serum MDA levels were lower in Group D compared to the other groups $(p<0.05)$.

Conclusion: We detected that dexketoprofen decreases I/R injury in both the torsion-formed testicle and the contralateral testicle. Thus, in patients who have urgent surgery for testicular detorsion, dexketoprofen can be preferred as an analgesic to reduce I/R injury. Further study is warranted to demonstrate this effect of dexketoprofen (Tab. 3, Fig. 1, Ref. 30). Text in PDF www.elis.sk.

Key words: testicle, ischemia-reperfusion injury, dexketoprofen.
\end{abstract}

Ischemia is the decrease of organ or tissue perfusion due to arterial or venous blood flow insufficiency. As a result, because tissues and organs become oxygen deficient, energy stores in cells empty, and following the accumulation of toxic materials, cell death occurs. Reperfusion is the return of blood supply and oxygenation of ischemic tissue. Reperfusion of ischemic tissue paradoxically causes much more severe damage in the tissue compared to ischemic injury only, a condition called ischemia/ reperfusion (I/R) injury (1). In particular, reactive oxygen species (ROS), which forms rapidly upon molecular oxygen entrance into the cell, and many other factors, such as arachidonic acid metabolites, nitric oxide, endothelin, complements, cytokines, and adhesion molecules, are responsible for I/R injury (2).

Testicular torsion is seen especially in newborns, children, and adolescents, and it requires urgent surgery. I/R injury following testicular torsion may cause infertility by affecting spermatic germ cells (3). Various antioxidants have been used to prevent I/R injury in

${ }^{1}$ Ondokuz Mayis University, Faculty of Medicine, Department of Anesthesiology, Samsun, Turkey, ${ }^{2}$ Ondokuz Mayis University, Faculty of Veterinary Medicine, Department of Pharmacology, Samsun, Turkey, ${ }^{3} \mathrm{On}-$ dokuz Mayis University, Faculty of Veterinary Medicine, Department of Pathology, Samsun, Turkey, and ${ }^{4}$ Ondokuz Mayis University, Faculty of Medicine, Department of Biochemistry, Samsun, Turkey

Address for correspondence: D. Karakaya, MD, Ondokuz Mayis University, Faculty of Medicine, Department of Anesthesiology, Samsun, Turkey. Phone: +905337343444, Fax: +903624576041

Acknowledgement: This research was financially supported by Ondokuz Mayis University Scientific Researches Projects (PYO. TIP. 1904.10.030). We thank Prof. Dr. Yüksel Bek for his statistical assistance of this manuscript. the testicle (4-6). Non-steroidal anti-inflammatory drugs (NSAID) have also been shown to have antioxidant effects by reducing ROS and/or reactive nitrogen species (RNS) (7). Dexketoprofen is an active enantiomer of ketoprofen, which is a racemic mixture from the arylpropionic acid family of NSAIDs. However, the effects of dexketoprofen on testicular I/R injury is not known. Therefore, the purpose of this study was to show the effects of dexketoprofen on $\mathrm{I} / \mathrm{R}$ injury in rats following developed testicular torsion.

\section{Materials and methods}

This study was conducted on 24 Wistar albino-type, male rats, 12-16 weeks old, 250-300 g, following Ethical Board approval (2010/32) of Ondokuz Mayis University School of Medicine Medical and Surgical Research Center. During the study, all the rats were kept in different cages, in a natural environment, in light for 12 hours and in the dark for 12 hours, in $21 \pm 2{ }^{\circ} \mathrm{C}$ temperature and 50-60\% humidity. The rats were fed standard pellet bait and city tap water until the day of the experiment. This study was supported in the context of Ondokuz Mayis University Scientific Researches Projects (PYO. TIP. 1904. 10.030).

The dexketoprofen ampule contains ethanol, sodium chloride, sodium hydroxide, and water for injection. Because the preservative materials in the drug may affect cell injury in the I/ R model, the active ingredient in dexketoprofen was supplied as pure powder from Menarini Ricerchere S.P.A. Sede e Laboratory (Pomezia, Rome). Powder dexketoprofen trometamol was first dissolved in ultrasonic bath and prepared $25 \mathrm{mg} / \mathrm{cc}$ aliquots. 
Tab. 1. Histopathologic assessment parameters (8).

\begin{tabular}{l}
\hline Histopathologic parameters \\
\hline Degeneration and necrosis in spermatogenic cells \\
Disorganization in spermatogenic cells \\
Desquamation in spermatogenic cells \\
Tubule collapse and shrinkage \\
Tubular atrophy \\
Cellular infiltration in intertubular space \\
Liquid exudation in intertubular space \\
Fibrosis \\
\hline
\end{tabular}

\section{Surgical procedure}

All the rats, except the control group, were anesthetized with intraperitoneal $5-10 \mathrm{mg} / \mathrm{kg}$ xylazine and $50-70 \mathrm{mg} / \mathrm{kg}$ ketamine hydrochloride, and taken to the experiment bench. After washing the scrotum with $10 \%$ povidone iodine solution, a vertical dermal and subdermal, $2 \mathrm{~cm}$ in length cut was made in the midline. In the scrotal space, the right testicle, tunica vaginalis and spermatic cord were evacuated and separated from the gubernaculum via blunt dissection. The right testicle, with cord components, was rotated $720^{\circ}$ clockwise, and an experimental extravaginal testicular torsion model was made. The torsioned testicle was stabilized to the inner surface of the scrotum with $6 / 0$ propylene stitches, and the scrotum was sutured. Five hours after torsion, the scrotum was reopened and the testicle was detorsioned and replaced into the scrotum.

\section{Groups}

The 24 rats were separated into three groups of eight rats each. The control group (Group C) had no surgical intervention, and it was used for basal values. Intraperitoneal $25 \mathrm{mg} / \mathrm{kg}$ dexketoprofen $(1 \mathrm{cc})$ (Group D) or the same volume of serum physiologic (Group SP) was given to the other groups 40 minutes before and 12 hours after detorsion.

Twenty-four hours after detorsion, bilateral orchiectomy was performed, $5 \mathrm{cc}$ intracardiac blood was drawn, and the rats were euthanized via cervical dislocation.

\section{Preparation of testicular tissues and serum}

The testicular tissue obtained via orchiectomy was cut into two pieces with a knife. The first piece was stabilized by being kept in Bouin solution for 24-48 hours for histologic assessment. The second piece was saved for biochemical investigation. The tissue samples $(0.10-0.20 \mathrm{~g})$ were washed several times in serum physiologic solution, dried with drying paper, placed in Eppendorf tubes, and stored at $-80^{\circ} \mathrm{C}$ until the day of biochemical investigation. The $5 \mathrm{cc}$ of blood drawn from the rats was centrifuged, and the serum and plasma were separated. The sera were put into two Eppendorf tubes and stored at $-80^{\circ} \mathrm{C}$.

\section{Histopathologic investigation}

The tissue samples were washed under a water stream for a day, then alcohol and xylol series were applied, and the samples were blocked in paraffin. Cross-sections 3-5 $\mu \mathrm{m}$ thick were taken with a Microtome (Leica RM2125RT) and were stained with hematoxylin-eosin (HE) for routine histopathologic evaluation. Histopathologic evaluations were conducted separately for every parameter $(0$ : none, 1: mild, 2: moderate, 3: severe) (8), as shown in Table 1, via Nikon Eclipse E600W light microscope, by the same pathologist.

\section{Biochemical evaluation}

For biochemical evaluation, levels of malondialdehyde (MDA), which is a lipid peroxidation product, were measured in the serum and testicular tissue. When all sampling was completed, the tissues were homogenized in an automatic tissue homogenizator and thawed. MDA levels in the testicular tissue were calculated as $\mu \mathrm{mol} /$ gr protein unit via the high-performance liquid chromatography (HPLC) (Agilent 1100 series DE14904147 instrument) method. Serum MDA levels were also measured with the same method.

\section{Statistical analysis}

The statistical analysis was performed using Statistical Package for SPSS Version 15 for Windows. All results were expressed as mean \pm SD. Differences between groups were compared by Kruskal-Wallis and Mann-Whitney $U$ tests. Ipsilateral and contralateral data within groups were compared by Wilcoxon test. A value of $\mathrm{p}<0.05$ was considered significant.

\section{Results}

During the time of torsion, edema and color changes due to venous stasis were observed in all operated testicles as the macroscopic view of ischemia. Degeneration, necrosis, disorganization, and desquamation were not seen in the spermatogenic cells in the Group C testicles.

The mean histopathologic evaluation scores of the testicular tissues obtained from all groups are shown in Table 2. Spermatogenic cells in the torsioned testicles of Group SP demonstrated

Tab. 2. Testicular histopathologic evaluation (mean \pm SD).

\begin{tabular}{|c|c|c|c|c|}
\hline & \multicolumn{2}{|c|}{ Group SP } & \multicolumn{2}{|c|}{ Group D } \\
\hline & Torsioned testicle & Contralateral testicle & Torsioned testicle & Contralateral testicle \\
\hline Degeneration and necrosis in spermatogenic cells & $2.62 \pm 0.74^{*}$ & $0.00 \pm 0.00$ & $1.12 \pm 1.24^{*}, \#$ & $0.25 \pm 0.70$ \\
\hline Disorganization in spermatogenic cells & $2.50 \pm 0.92^{*}$ & $0.00 \pm 0.00$ & $1.12 \pm 1.24^{*, \#}$ & $0.25 \pm 0.70$ \\
\hline Desquamation in spermatogenic cells & $2.50 \pm 0.92^{*}$ & $0.00 \pm 0.00$ & $1.12 \pm 1.24^{*}, \#$ & $0.25 \pm 0.70$ \\
\hline Tubule collapse and shrinkage & $1.12 \pm 1.12^{*}$ & $0.00 \pm 0.00$ & $0.50 \pm 1.06$ & $0.00 \pm 0.00$ \\
\hline Tubular atrophy & $0.75 \pm 0.88$ & $0.00 \pm 0.00$ & $0.50 \pm 1.06$ & $0.00 \pm 0.00$ \\
\hline Cellular infiltration in intertubular space & $1.37 \pm 1.30^{*}$ & $0.00 \pm 0.00$ & $0.87 \pm 1.12$ & $1.12 \pm 0.35$ \\
\hline Fibrosis & $0.37 \pm 0.74$ & $0.00 \pm 0.00$ & $1.12 \pm 0.35$ & $0.00 \pm 0.00$ \\
\hline
\end{tabular}

${ }^{*} \mathrm{p}<0.05$, compared to contralateral testicle in the same group, ${ }^{*} \mathrm{p}<0.05$, compared to torsioned testicle in Group SP 
Tab. 3. MDA levels in testicular tissue ( $\mu \mathrm{mol} / \mathrm{gr}$ protein) and serum $(\mathrm{g} / \mathrm{L})($ mean \pm SD).

\begin{tabular}{lccc}
\hline & Torsioned testicle & Contralateral testicle & Serum \\
\hline Group C & $0.53 \pm 0.57$ & $0.69 \pm 0.56$ & $0.54 \pm 0.24$ \\
Group SP & $1.77 \pm 2.46$ & $1.56 \pm 1.27$ & $0.48 \pm 0.10$ \\
Group D & $0.42 \pm 0.27$ & $0.65 \pm 0.40$ & $0.25 \pm 0.06^{*}, * *$ \\
\hline$* \mathrm{p}=0.02$, compared to Group C, $* * \mathrm{p}=0.01$, compared to Group SP
\end{tabular}

mild to severe degeneration, necrosis, disorganization, and desquamation (Fig. 1). Injury in the spermatogenic cells in both the Group SP and Group D torsioned testicles was greater than in the normal testicles $(\mathrm{p}<0.05)$. However, degeneration, necrosis, disorganization, and desquamation in the Group D spermatic cells were significantly lower than in Group SP $(p<0.05)$.

In Group SP, MDA levels in both the torsioned and contralateral testicles were higher than in the other groups (Tab. 3). MDA levels in both testicular tissues in Group D were similar to the control group. Although they were lower than Group SP, the difference was not statistically significant. However, the serum MDA levels in Group D were statistically lower than in the other groups $(\mathrm{p}<0.05)$.

\section{Discussion}

Testicular torsion is a urological emergency that requires urgent diagnosis and treatment. For testicular ischemia to be eliminated, surgical detorsion should be performed as early as possible. Persistence of testicular tissue vitality without atrophy is related to the duration of the ischemia (9). However, detorsion does not prevent injury completely. Following detorsion, free oxygen radicals are generated as a result of ischemic tissue reperfusion. Those free oxygen radicals produce a two-phase effect. The first phase occurs shortly after the reperfusion and lasts for several hours. During this phase, production of ROS increases in the mitochondria, and they react with the lipids in cell membranes and initiate lipid peroxidation (10). The second phase lasts for hours and even days, and it is characterized by neutrophil infiltration and inflammation (11). All these events are responsible for I/R injury. Testicles are very sensitive to injury from free oxygen radicals (3).

The main purpose of surgical detorsion in the treatment of testicular torsion is to reduce the effects of I/R injury. One of the effective agents is antioxidants (6). The effects of NSAIDs, which inhibit cyclooxygenase (COX), are thought to be partially related to ROS/RNS decline and neutrophil release prevention (7). Various studies have been conducted on the preventive effects of NSAIDs against I/R injury. Dokmeci et al (12) showed that ibuprofen decreases mitochondrial degeneration in Sertoli and spermatic cells and reduces MDA levels. It has been shown that the use of antioxidant (L-carnitine) and COX-2 inhibitor (meloxicam) together reduces the cellular injury that occurs after testicular torsion (13). Ketoprofen has been shown to decrease the infarct area in focal cerebral ischemia (14). Besides its anti-inflammatory and antioxidant features, ketoprofen also inhibits neutrophil aggregation and degranulation. Dexketoprofen is an NSAID that is more lipophilic than ketoprofen and has a higher solubility due to additional trometamol on its molecule, and it is an active enantiomer of ketoprofen. Its effect starts more quickly, and it has fewer gastroin-

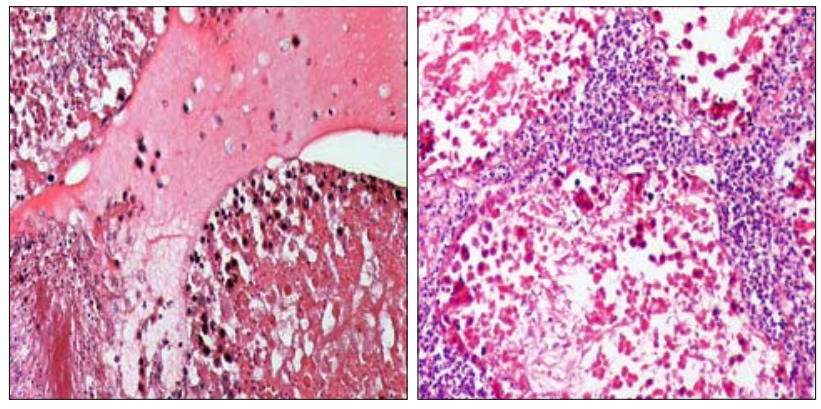

Fig. 1. Degeneration, necrosis in tubules, and intertubular edema (left); necrosis in tubules and interstitial neutrophil infiltration (right).

testinal side effects (15). However, there have been no studies on the effects of dexketoprofen on $\mathrm{I} / \mathrm{R}$ injury.

Vascular permeability increases in tissue and cells exposed to hypoxia; intra- and extracellular edema occur, leading to cell apoptosis and death. Free oxygen radicals that form during this period may also cause infertility via important physiopathologic changes in the spermatogenic cells. Mogilner et al (16) showed that testicular ischemia in rats caused histological injury. Moreover, testicular ischemia has been shown to cause an increase in germ cell apoptosis in the contralateral testicle. Dokucu et al (17) also detected an increase in histological injury and edema in testicular torsion, except in the Leydig cells in the ruptured tubules. Similarly, we also found histopathologic changes in the spermatogenic cells as a result of I/R caused by testicular torsion. However, we did not detect any significant change in the tubules. In the group that was given dexketoprofen, spermatogenic cell injury markedly declined. In the pathogenesis of testicular I/R injury, three isoforms of nitrite oxide synthase (NOS) are shown to be responsible (18). The source of NOS is interstitial cells and macrophages that infiltrate around the injured tubules. In addition to free oxygen radicals and NOS, activated neutrophils, inflammatory cytokines, and adhesion molecules are also responsible for testicular I/R injury (19). Dexketoprofen might also decrease spermatogenic cell injury via its anti-inflammatory features. The histological changes that appeared are related to both the duration of ischemia and the time of reperfusion (20). To prevent possible effects on the experimental I/R injury from the preservative substances (ethanol, sodium chloride, and sodium hydroxide) in the dexketoprofen ampule, we used a pure active ingredient.

There are different opinions about the effects of testicular torsion on the contralateral testicle. It has been suggested that ipsilateral testicular torsion may cause oxidative stress and injury in the contralateral testicle. Several mechanisms, such as an increase in biomarkers that cause DNA changes (21), apoptosis (22), free oxygen radical secretion from the testicle (23), reflex decrease in contralateral testicle blood flow (24), and autoimmunization by the destroyed blood-testicle barrier (25), have been described. However, other studies were unable to show injury in the contralateral testicle $(26,27)$. In the current study, we did not detect any histopathologic changes in the contralateral testicle following $\mathrm{I} / \mathrm{R}$ in the ipsilateral testicle. However, an increase in the level of MDA, which is a lipid peroxidation product, in the contralateral testicle in Group SP might indicate some degree of biochemical I/R injury. 
Oxidative stress biomarkers form before physiologic and morphologic changes do (28). Malondialdehyde is an I/R injury product that forms during lipid peroxidation and is proportional to the degree of lipid peroxidation (29). Raju et al (30) demonstrated that MDA reached its maximum degree in testicles following 4-hour ischemia and 4-hour reperfusion. We applied 24-hour reperfusion, followed by a 5-hour ischemia period. In this study, MDA levels in both the torsioned and contralateral testicles in the group taking dexketoprofen were less than those of Group SP, but that result was not statistically significant. In addition, the significant decrease in serum MDA level in the group taking dexketoprofen shows that it decreases I/R injury. With these findings, we demonstrated that dexketoprofen is effective in decreasing $I / R$ injury in the contralateral testicle. The reason there was no statistically significant difference in MDA levels in the testicular tissues may be the small number of rats.

In this study, we investigated the effects of two-dose dexketoprofen on I/R injury in testicles, and we discovered that it decreases pathologic changes in the spermatogenic cells and serum MDA levels in testicular torsion. We believe that administering dexketoprofen to patients who will be operated on to correct testicular torsion might decrease $\mathrm{I} / \mathrm{R}$ injury. Further study is warranted to prove this effect of dexketoprofen.

\section{References}

1. Zimmerman BJ, Granger DN. Reperfusion injury. Surg Clin North Am 1992; 72 (1): 65-83.

2. Monsinjon T, Richard V, Fontaine M. Complement and its implications in cardiac ischemia/reperfusion: Strategies to inhibit complement. Fundam Clin Pharmacol 2001; 15 (5): 293-306.

3. Filho DW, Torres MA, Bordin AL, Crezcynski-Pasa TB, Boveris A. Spermatic cord torsion, reactive oxygen and nitrogen species and ischemiareperfusion injury. Mol Aspects Med 2004; 25 (1-2): 199-210.

4. Akgur FM, Kilinc K, Aktug T, Olguner M. The effect of allopurinol pretreatment before detorting testicular torsion. J Urol 1994; 151 (6): 1715-1717.

5. Orozco TJ, Wang JF, Keen CL. Chronic consumption of a flavanol- and procyanindin-rich diet is associated with reduced levels of 8-hydroxy-2'deoxyguanosine in rat testes. J Nutr Biochem 2003; 14 (2): 104-110.

6. Ozkan KU, Boran C, Kilinc M, Garipardic M, Kurutas EB. The effect of zinc aspartate pretreatment on ischemia-reperfusion injury and early changes of blood and tissue antioxidant enzyme activities after unilateral testicular torsion-detorsion. J Pediatr Surg 2004; 39 (1): 91-95.

7. Costa D, Moutinho L, Lima JL, Fernandes E. Antioxidant activity and inhibition of human neutrophil oxidative burst mediated by arylpropionic acid non-steroidal anti-inflammatory drugs. Biol Pharm Bull 2006; 29 (8): $1659-1670$.

8. Russell LD, SinhaHikim AP, Ettlin RA, Clegg ED (Eds). Histological and histopatological evaluation of the testis. Florida; Cache River Press, 1990.

9. Makela E, Lahdes-Vasama T, Rajakorpi H, Wikstrom S. A 19-year review of paediatric patients with acute scrotum. Scand J Surg 2007; 96 (1): 62-66.

10. Yamato M, Egashira T, Utsumi H. Application of in vivo ESR spectroscopy to measurement of cerebrovascular ros generation in stroke. Free Radic Biol Med 2003; 35 (12): 1619-1631.

11. Cutrin JC, Boveris A, Zingaro B, Corvetti G, Poli G. In situ determination by surface chemiluminescence of temporal relationships between evolving warm ischemia-reperfusion injury in rat liver and phagocyte activation and recruitment. Hepatology 2000; 31 (3): 622-632.
12. Dokmeci D, Kanter M, Inan M, Aydogdu N, Basaran UN, Yalcin O, Turan FN. Protective effects of ibuprofen on testicular torsion/detorsion-induced ischemia/reperfusion injury in rats. Arch Toxicol 2007; 81 (9): 655-663.

13. Gurocak S, Yilmaz A, Alp E, Ure I, Sozen S, Menevse S, Menevse A, Bozkirli I. Inflammation and oxidative stress in testicular torsion: Do they deserve intensive treatment to save both guilty and innocent testes? Urology 2011; 78 (1): 164-169.

14. Dias LA, Colli BO, Coutinho Netto J, Lachat JJ. [focal cerebral ischaemia induced by middle cerebral artery occlusion and the neuroprotective effect of ketoprofen in rats]. Arq Neuro-psiquiatr 2000; 58 (4): 1047-1054.

15. Barbanoj MJ, Antonijoan RM, Gich I. Clinical pharmacokinetics of dexketoprofen. Clin Pharmacokinet 2001; 40 (4): 245-262.

16. Mogilner JG, Lurie M, Coran AG, Nativ O, Shiloni E, Sukhotnik I. Effect of diclofenac on germ cell apoptosis following testicular ischemiareperfusion injury in a rat. Pediatr Surg Int 2006; 22 (1): 99-105.

17. Dokucu AI, Ozturk H, Ozdemir E, Ketani A, Buyukbayram H, Yucesan $\mathbf{S}$. The protective effects of nitric oxide on the contralateral testis in prepubertal rats with unilateral testicular torsion. BJU Int 2000; 85 (6): 767-771.

18. Moon C, Ahn M, Kim S, Yasuzumi F, Shin T. Increased expression of both constitutive and inducible forms of nitric oxide synthase in the delayed phase of acute experimental testicular torsion. J Vet Med Sci 2005; 67 (4): 453-456.

19. Shiraishi K, Naito K, Yoshida K. Nitric oxide promotes germ cell necrosis in the delayed phase after experimental testicular torsion of rat. Biol Reprod 2001; 65 (2): 514-521.

20. Saba M, Morales CR, De Lamirande E, Gagnon C. Morphological and biochemical changes following acute unilateral testicular torsion in prepubertal rats. J Urol 1997; 157 (3): 1149-1154.

21. Carroll TA, Regan MC, Alyusuf R, Greene D, Curran B, Kay E, Leader M, Fitzpatrick JM. Determination of testicular function after torsion by DNA flow cytometry of serial fine-needle aspirates. Br J Urol 1997; 79 (3): 449-454.

22. Hadziselimovic F, Geneto R, Emmons LR. Increased apoptosis in the contralateral testis in patients with testicular torsion. Lancet. 1997; 350: 118 23. Bulkley GB. Free radical-mediated reperfusion injury: A selective review. Br J Cancer Suppl 1987; 8: 66-73.

24. Ciftci AO, Muftuoglu S, Cakar N, Tanyel FC. Histological evidence of decreased contralateral testicular blood flow during ipsilateral testicular torsion. Br J Urol 1997; 80 (5): 783-786.

25. Harrison RG, Lewis-Jones DI, Moreno de Marval MJ, Connolly RC. Mechanism of damage to the contralateral testis in rats with an ischaemic testis. Lancet 1981; 2 (8249): 723-725.

26. Turner TT, Brown KJ. Spermatic cord torsion: Loss of spermatogenesis despite return of blood flow. Biol Reprod 1993; 49 (2): 401-407.

27. Bozlu M, Coskun B, Cayan S, Acar D, Aktas S, Ulusoy E, Akbay E. Inhibition of poly(adenosine diphosphate-ribose) polymerase decreases long-term histologic damage in testicular ischemia-reperfusion injury. Urology 2004; 63 (4): 791-795.

28. Pedrosa RC, De Bem AF, Locatelli C, Geremias R, Wilhelm Filho D. Time-dependent oxidative stress caused by benznidazole. Redox Rep 2001; 6 (4): 265-270.

29. Draper HH, Hadley M. Malondialdehyde determination as index of lipid peroxidation. Methods Enzymol 1990; 186: 421-431.

30. Raju AB, Challa SR, Akula A, Kiran K, Harinadh GB. Evaluation of oxidant and anti-oxidant balance in experimentally induced testicular injury by ischemia reperfusion in rat. Eur J Gen Med 2011; 8 (2): 117-121.

Received December 21, 2012. Accepted February 28, 2014. 